\title{
ANÁLISE DA ESTRUTURA PRODUTIVA E SUAS OPORTUNIDADES DE EMPREENDER ADJACENTES NO MUNICÍPIO DE CORUMBÁ (MS)
}

Raul Castelao ${ }^{1}$

Roosiley Santos Souza ${ }^{2}$

Alessandra Trotta ${ }^{2}$

${ }^{1}$ Faculdade Salesiana de Santa Teresa

${ }^{2}$ Universidade Federal de Mato Grosso do Sul 


\title{
ANÁLISE DA ESTRUTURA PRODUTIVA E SUAS OPORTUNIDADES DE EMPREENDER ADJACENTES NO MUNICÍPIO DE CORUMBÁ (MS)
}

\author{
Raul Asseff Castelao ${ }^{1}$ \\ Roosiley Santos Souza ${ }^{2}$ \\ Alessandra Trotta ${ }^{2}$ \\ ${ }^{I}$ Faculdade Salesiana de Santa Teresa \\ ${ }^{2}$ Universidade Federal de Mato Grosso do Sul
}

\begin{abstract}
Resumo: Este artigo procurou descrever a estrutura produtiva do município de Corumbá e, a partir disso, identificar oportunidades de se empreender localmente. Para tanto, com base nos dados da RAIS e CAGED apresentamos o perfil do porte das empresas no município e a complexidade produtiva e, em seguida, calculamos o quociente locacional de ocupações e de empresas, o coeficiente de localização e de especialização. Com isso identificarmos a estrutura produtiva e quais as oportunidades de empreendedorismo que derivam desta estrutura. De modo a fundamentarmos a relação entra a estrutura produtiva e o empreendedorismo, apresentamos referencial teórico no sentido de demonstrar a interação entre estas duas áreas e como as políticas públicas podem contribuir para o estímulo do empreendedorismo regionalmente. Sendo assim, conclui-se que $98 \%$ das empresas no município são MPE e as oportunidades adjacentes se estabelecem como produtos e serviços de alta complexidade, podendo gerar maior valor agregado a economia local.
\end{abstract}

Palavras-chave: Estrutura produtiva. Empreendedorismo. Oportunidades.

\section{Introdução}

O município de Corumbá é uma das 79 cidades do Estado do Mato Grosso do Sul e, conforme dados do Instituto Brasileiro de Geografia e Estatística (IBGE), o município possuía em 2010, ano do último censo, 103.703 habitantes e em 2017, 109.899 habitantes, sendo a quarta mais populosa do Estado e com uma variação de $8,36 \%$ de crescimento populacional em relação ao censo de 2000. A cidade conta com mais de 10 mil habitantes vivendo na zona rural, por causa do grande número de fazendas presentes na região.

Em termos econômicos, seu PIB, a preços correntes, em 2014 (último dado disponibilizado) é de $\mathrm{R} \$ 3.101 .210,4$ sendo o quarto do Estado. O município registra uma taxa média de crescimento de $16 \%$ entre 2002 a 2014 e, entre os anos de 2013/2014 o aumento foi de $16 \%$.

Em se tratando da composição do PIB do município, este sofre um revés de mudança no meio da década de 1980 , aonde até este período, $35 \%$ de toda produção era originada no

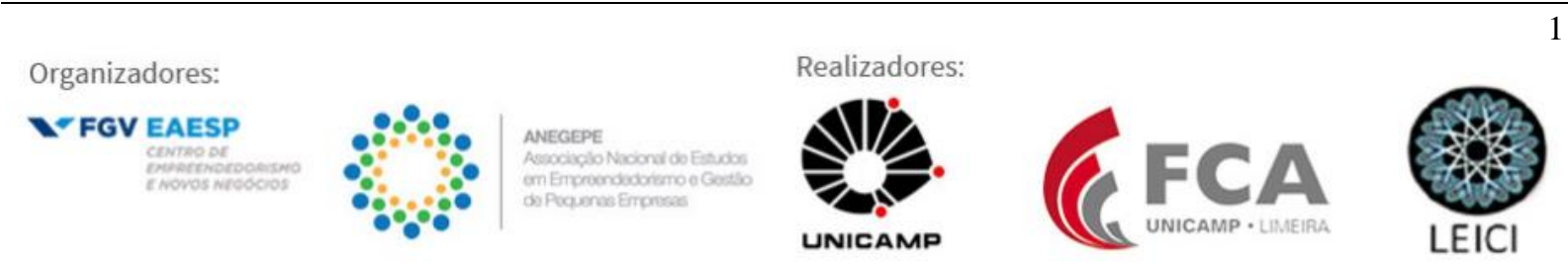


agronegócio. A partir de 1985, a matriz econômica de Corumbá passa a ter o setor de serviços com maior peso em sua composição, promovendo então a reversão da base produtiva local.

Ao levarmos em consideração a variação ano a ano em termos relativos e extrairmos a média, o setor do agronegócio registrou uma variação negativa quanto à participação no PIB municipal de $-5 \%$, o setor de serviços não registrou ganho ou perda entre 2000 e 2010 enquanto que, a indústria, obteve $8 \%$ de variação no respectivo período.

Diante dos dados expostos, torna-se pertinente desenvolver este estudo com os seguintes objetivos:

1. Identificar e descrever padrões de concentração ou dispersão espacial, a partir de atividade econômica (análise da estrutura produtiva local);

2. Apresentar possíveis hipóteses de alternativas de empreendedorismo para o desenvolvimento local do município.

Desta maneira, nos propusemos a contribuir com a busca por uma hipótese de qual é a vocação econômica de Corumbá (MS) que, neste estudo, se baseia em métodos de análise de economia regional e relacionando como o empreendedorismo pode estar presente neste processo.

Neste sentido, o estudo se limita a uma análise na condição ceteris paribus em relação a dinâmica da economia de Corumbá diante da economia do Estado do Mato Grosso do Sul nos anos de 1990, 2000 e 2010.

\section{Referencial Teórico}

\section{POLÍTICA PÚBLICA, EMPREENDEDORISMO LOCAL E ESTRUTURA PRODUTIVA}

De maneira geral, é possível afirmar que fatores como nível de educação, pesquisas e desenvolvimento, aumento do nível de tecnologia empregada no setor produtivo, inovação e empreendedorismo podem conduzir o crescimento econômico (ALMEIDA, 2017). A partir da combinação destes fatores torna-se viável a construção de ambiente favorável ao crescimento econômico, promovendo a geração de emprego e renda (LEYDEN, \& LINK, 2015).

Neste sentido, é público notório que o empreendedorismo se tornou um tema atual no cerne ao crescimento econômico das localidades (NETO et al., 2017). Contudo, o debate sobre a necessidade de se estudar a construção de políticas públicas com o intuito de fomentar o empreendedorismo parte do entendimento de que as micro e pequenas empresas possuem participação significante na economia nacional e regionais (SARFATI, 2013.)

A criação de políticas públicas que procuram fomentar empreendedores possui o efeito de permitir a criação de novos empregos, com a possibilidade de maior valor agregado e, desta forma, contribuir com o crescimento econômico (HENREKSON e STENKULA, 2009).

No Brasil, conforme dados do relatório do Global Entrepreneurship Monitor (GEM) do ano base de 2016, 48 milhões de pessoas no Brasil têm um negócio ou estão envolvidos na criação de um e o número médio de porcentagem de empreendedores no país é de 27,72\% em porcentagem da população adulta (GEM, 2017).
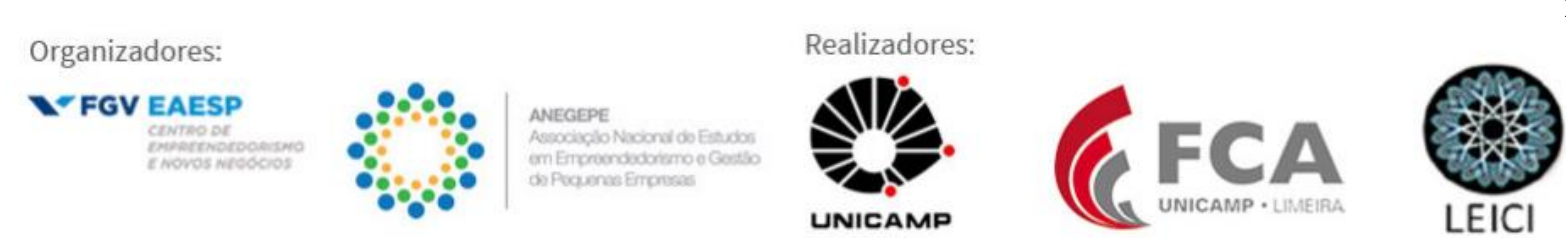
Desta forma, o empreendedorismo passa a ser reconhecido como estratégia regional para que se possam gerar novas oportunidades de crescimento econômico demandando, portanto, políticas públicas de fomento e manutenção da atividade empreendedora (SARFATI, 2013).

De maneira complementar, Gomes et al. (2013), afirmam que as ações articuladas do governo possuem a capacidade de produzirem um ambiente favorável ao empreendedorismo sendo que, o empreender passa a constituir peça importante do motor da economia e, por conseguinte, do desenvolvimento econômico e social.

SARFATI (2013) descreve que as políticas públicas voltadas ao empreendedorismo precisam refletir a realidade das localidades, seu contexto social e econômico para que o apoio ao empreender tenha efeito assertivo.

De acordo com Souza (2015) o empreendedorismo, é visto como o "promotor da geração de novos conhecimentos, de novas tecnologias, tendo a capacidade de potencializar o papel dos empreendedores na sociedade como agentes de desenvolvimento em seu contexto local e regional".

Neste sentido, a OCDE (2010) apresenta algumas dificuldades ou condicionantes que podem direcionar a atividade empreendedora: mudanças demográficas, mudanças sociais, mudanças econômicas, mudanças regulatórias e etc. Desta forma, a compreensão e real conhecimento da estrutura produtiva local pode ser uma informação que venha a contribuir como o empreendedorismo das regiões.

Reconhecida a importância do empreendedorismo enquanto vetor de crescimento e desenvolvimento, de modo a estimular a criação de políticas públicas em prol do empreendedorismo como instrumento de desenvolvimento local, é necessário a compreensão da estrutura produtiva de modo a obter maior eficiência no que tange a assertividade das políticas públicas.

De modo que seja possível o desenvolvimento econômico em determinada localidade e é necessário a mudança uma mudança estrutural no setor produtivo com o objetivo de garantir que os insumos de uma economia se destinem a setores mais modernos, com maior complexidade econômica (RODRICK, 2013).

Na década de 1980, o estudo das diferenças setoriais nos setores produtivos passou a ganhar destaque contra o mainstrean em voga à época, de que as oportunidades de crescimento e desenvolvimento econômico fosse a partir da modelagem de funções de produção (FIGUEIREDO e OLIVEIRA, 2015).

Um conjunto de medidas descritivas e de natureza eminentemente exploratórias são comumente utilizados em diagnósticos do processo de mudança estrutural dos setores produtivos, definindo os padrões regionais da distribuição espacial das atividades econômicas. Tais medidas podem ser divididas entre medidas de localização, de natureza setorial, que procuram verificar padrões de concentração ou dispersão espacial. Já as medidas de especialização concentram a análise na estrutura produtiva de cada região objetivando analisar o grau de especialização regional, assim como sua mudança para determinados períodos de tempo (LIMA et. al, 2006).

Sendo assim, o conhecimento da estrutura produtiva de determinada localidade pode subsidiar a criação de políticas públicas que permitam o estímulo maior e, de forma assertiva,
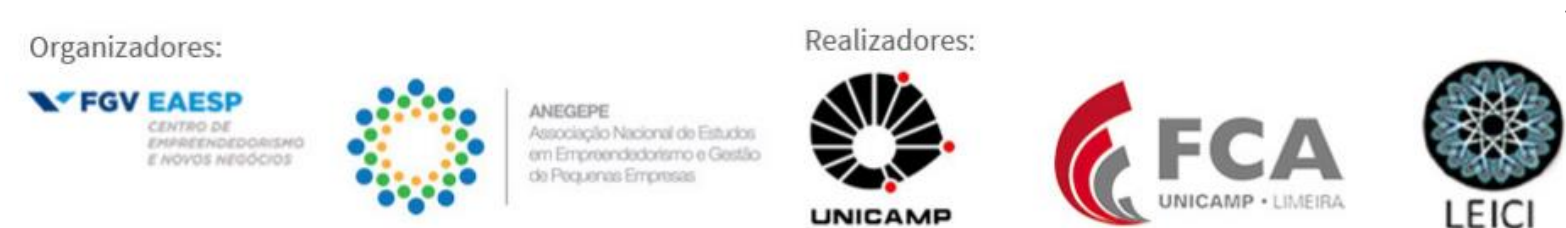
ao empreendedorismo, sendo este, um instrumento de estímulo ao crescimento econômico sendo, portanto, indutor enquanto ferramenta de crescimento e desenvolvimento local.

\section{Método e Técnicas de Pesquisa}

O estudo reúne o uso de três indicadores de especialização e concentração econômica regional amplamente empregadas em estudos de caracterização e dinâmica econômica regional (quociente locacional de ocupação e de estabelecimentos, coeficiente de localização e coeficiente de especialidade).

Conforme Haddad (1989), Piacenti e Ferrera de Lima (2002) e Costa (2002), estas medidas são úteis para o conhecimento dos padrões do crescimento econômico das mesorregiões (LIMA et. al, 2006). No quadro 1 apresentamos os indicadores, suas respectivas equações e a interpretação dos resultados.

Quadro 1. Descrição das medias de localização e especialização

\begin{tabular}{|l|c|l|}
\hline \multicolumn{1}{|c|}{ Indicador } & Equação & \multicolumn{1}{|c|}{ Interpretação dos resultados } \\
\hline $\begin{array}{l}\text { Quociente locacional (QL) de } \\
\text { ocupação }\end{array}$ & $Q L_{i j}=\frac{E_{i j} / \sum_{i} E_{i j}}{\sum_{j} E_{i j} / \sum_{i} \sum_{j} E_{i j}}$ & $\begin{array}{l}\mathrm{QL} \geq 1=\text { localização significativa } \\
0,5 \leq \mathrm{QL} \leq 0,99=\text { localização média } \\
\mathrm{QL} \leq 0,49=\text { localização fraca }\end{array}$ \\
\hline Coeficiente de Localização (CL) & $C L_{i}=\frac{\sum_{j}\left(E_{i j} / \sum_{j} E_{i j}\right)-\left(\sum_{i} E_{i j} / \sum_{i} \sum_{j} E_{i j}\right)}{2}$ & $\begin{array}{l}\text { Próximo a 0 = dispersão significativa } \\
\text { Próximo a 1 = concentração } \\
\text { significativa }\end{array}$ \\
\hline Coeficiente de Especialização (CE) & $C E_{j}=\frac{E_{i j} / \sum_{j} E_{i j}}{\sum_{i} E_{i j} / \sum_{i} \sum_{j} E_{i j}}$ & $\begin{array}{l}\text { Próximo a 0 = dispersão significativa } \\
\text { Próximo a 1 = especialização } \\
\text { significativa }\end{array}$ \\
\hline
\end{tabular}

Fonte: Elaboração própria.

Dentre as medidas de localização Haddad (1989) utiliza o quociente locacional (QL) para comparar a participação percentual de uma região em um setor particular com a participação percentual da mesma região no total do emprego da economia de referência. Neste estudo calculamos também o quociente locacional do número de estabelecimentos para uma análise tanto da visão da mão de obra (demanda) quanto das empresas (oferta).

O objetivo do coeficiente de localização (CL) é relacionar a distribuição percentual da mão-de-obra num dado setor entre as mesorregiões, com a distribuição percentual da mão-deobra do estado (LIMA et. al, 2006). A partir dos resultados que possam resultar em um padrão de concentração das atividades econômicas, torna-se possível identificar um parâmetro de tendência à concentração espacial de determinadas atividades (FRAINER, et. al).

O coeficiente de especialização (CE) objetiva-se a comparar a estrutura produtiva da região ou da localidade, em termos da participação de cada setor no emprego total, com a estrutura produtiva do Estado nesses mesmos termos. A lógica dessa medida é muito

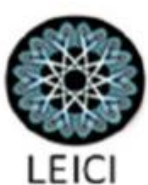


semelhante àquela que resulta no coeficiente de localização, porém agora aplicada para as diferentes regiões (LARA, et. al, 2010).

Para o cálculo dos indicadores de localização e especialização foram utilizados dados do emprego formal e número de estabelecimentos extraídos da base da relação anual de informações sociais (RAIS) do Ministério do Trabalho e Emprego.

\section{Resultados da Pesquisa}

Ao desagregarmos os dados referente as empresas no município, é possível verificar que as empresas de pequeno porte apresentam a maior taxa de crescimento entre os demais portes de empresas no município

Tabela 1. Empresas por porte e por ano

\begin{tabular}{c|cccccc} 
PORTE & $\mathbf{2 0 1 1}$ & $\mathbf{2 0 1 2}$ & $\mathbf{2 0 1 3}$ & $\mathbf{2 0 1 4}$ & $\mathbf{2 0 1 5}$ & $\mathbf{2 0 1 6}$ \\
\hline MICRO & $84 \%$ & $84 \%$ & $84 \%$ & $85 \%$ & $85 \%$ & $84 \%$ \\
PEQUENA & $13 \%$ & $13 \%$ & $13 \%$ & $13 \%$ & $13 \%$ & $15 \%$ \\
MÉDIA & $1 \%$ & $1 \%$ & $1 \%$ & $1 \%$ & $1 \%$ & $1 \%$ \\
GRANDE & $1 \%$ & $1 \%$ & $2 \%$ & $1 \%$ & $1 \%$ & $1 \%$ \\
TOTAL & $100 \%$ & $100 \%$ & $100 \%$ & $100 \%$ & $100 \%$ & $100 \%$
\end{tabular}

Fonte: Elaboração própria a partir de dados da RAIS (2017).

Nota-se que o perfil do porte empresarial no município é $98 \%$, em média, constituído de micro e pequenas empresas, reforçando a tendência de serem desenhadas políticas públicas de acordo com este perfil, otimizando assim recursos e ações com maior impacto.

A partir dos dados da RAIS, apresentamos na figura 1 o número de empregos formais por atividade econômica em porcentagem do total.

Figura 1. Porcentagem de empregos formais por setor

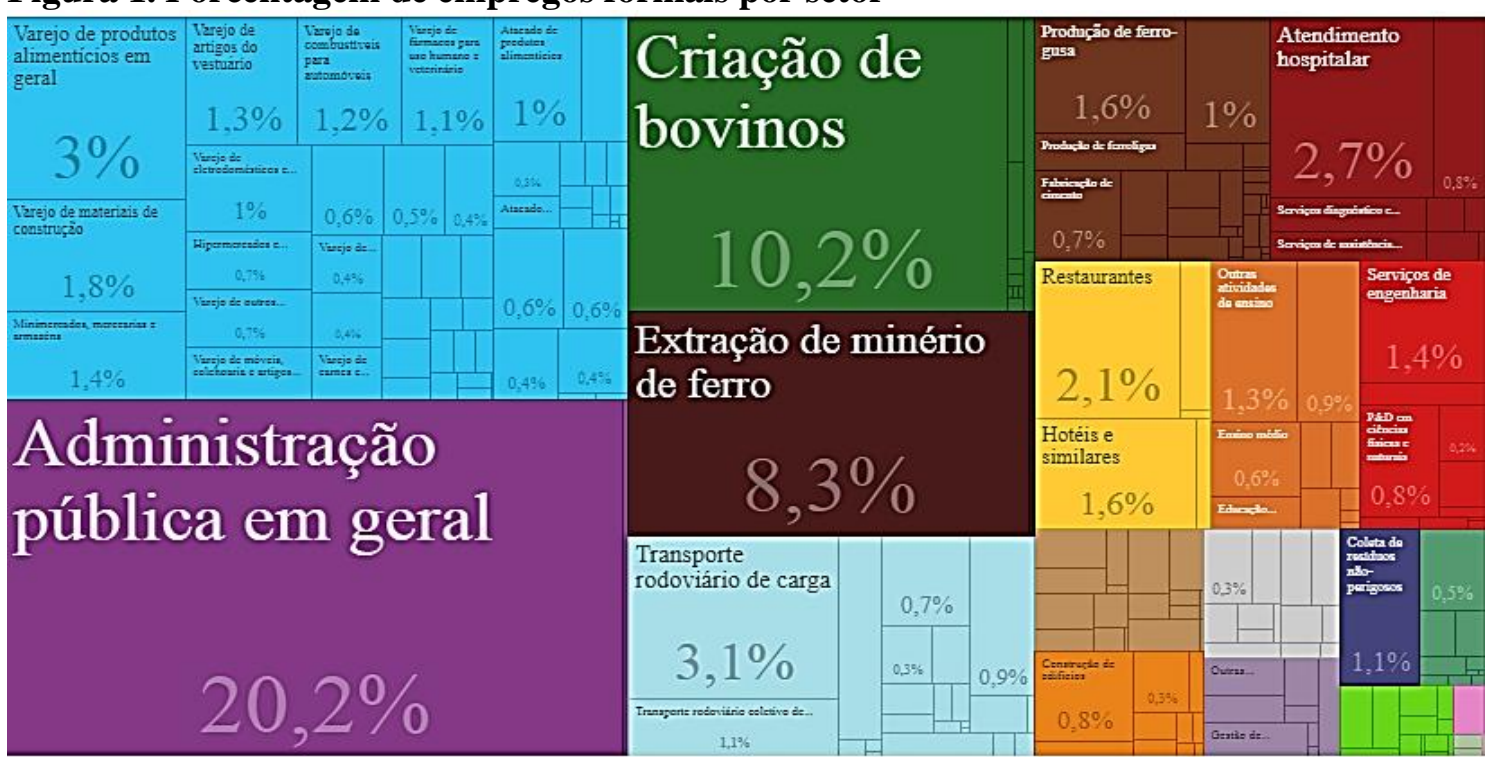

Fonte: RAIS (2016). 
A partir dos dados da Balança Comercial do município, nota-se que a maior parte dos produtos que fazem parte da pauta de exportação local são de baixa complexidade, o que implica na geração de emprego e renda, conforme apresentado na figura 2.

Figura 2. Dispersão da complexidade de produtos da pauta de exportação de Corumbá

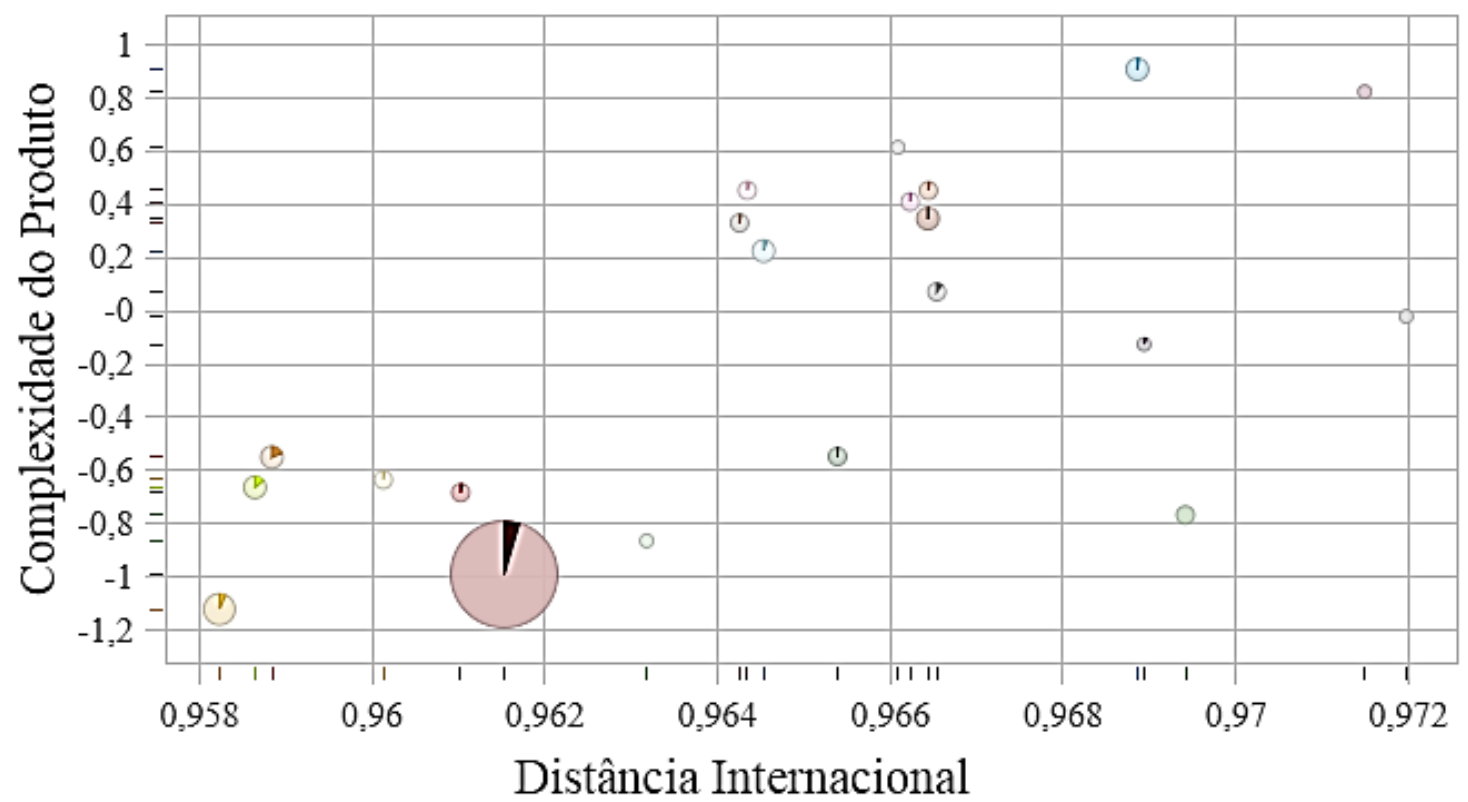

Fonte: RAIS; Data Viva (2016).

Em relação a baixa complexidade do produto é notório uma vez que o município possui em sua estrutura produtiva basicamente commodities, seja industrial ou do agronegócio.

\section{Quociente Locacional}

A primeira análise quanto a vocação estrutural econômica do município trata-se do quociente locacional. Entre os anos de 1990, 2000 e 2010, apenas quatro setores permaneceram como setores chaves, apresentados no quadro 2.

Quadro 2. Quociente Locacional do Emprego Formal

\begin{tabular}{|c|l|l|l|}
\hline SETOR & 1990 & 2000 & 2010 \\
\hline EXTRAÇÃO MINERAL & 10,89 & 10,63 & 16,39 \\
\hline MIN NAO MET & 4,27 & 2,05 & 1,41 \\
\hline IND METALURG & 4,72 & 2,24 & 1,43 \\
\hline TRAN E COMUM & 2,04 & 1,99 & 1,84 \\
\hline
\end{tabular}

Fonte: Dados da pesquisa

Em uma análise relativa, o setor que obteve maior variação entre os anos são os setores da construção civil (466\%) e alimentos e bebidas (205\%). No entanto, mesmo com o expressivo

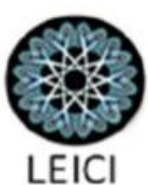


aumento, o quociente locacional destes setores não chega a caracterizá-lo como setor chave, sendo respectivamente 0,80 e 0,31 em 2010. Contudo, os setores da agropecuária e administração pública passam a se tornar setores chaves a partir de 2000 , registrando aumento na passagem para 2010, conforme o quadro 3.

Quadro 3. Quociente Locacional do Emprego Formal, por setores selecionados

\begin{tabular}{|c|c|c|c|}
\hline SETOR & 1990 & 2000 & 2010 \\
\hline ADMINISTRAÇÃO PUBLICA & 0,99 & 1,03 & 1,22 \\
\hline AGROPECUARIA & 0,34 & 1,39 & 1,42 \\
\hline CONSTRUÇÃO CIVIL & 0,44 & 0,14 & 0,80 \\
\hline ALIMENTOS E BEBIDAS & 0,21 & 0,10 & 0,31 \\
\hline
\end{tabular}

Fonte: Dados da pesquisa

Os resultados apresentados no quadro 2 apontam para uma especialização na Indústria Extrativa Mineral, contudo os setores da administração pública e agropecuária apresentam resultados interessantes a partir do ano de 2000 para 2010, revelando potencialidades de especialização nestes setores.

Ao analisarmos o quociente locacional a partir da utilização de variável o número de estabelecimentos, nota-se certa aproximação com o QL com base na variável ocupação, apresentados no quadro 4 .

Quadro 4. Quociente Locacional a partir do número de estabelecimentos

\begin{tabular}{|c|c|}
\hline SETOR & QL \\
\hline 01-Extrativa Mineral & 3,41 \\
\hline 06-Material de Transporte & 2,17 \\
\hline 04-Indústria Mecânica & 1,51 \\
\hline 20-Transporte e Comunicações & 1,45 \\
\hline 21-Alojamento/ Comuniação & 1,35 \\
\hline 23-Ensino & 1,32 \\
\hline 17-Comércio Atacadista & 1,31 \\
\hline 22-Médicos/ Odontológicos/ Veterinários & 1,14 \\
\hline 16-Comércio Varejista & 1,02 \\
\hline 08-Papel e Gráfica & 1,01 \\
\hline
\end{tabular}

Fonte: Dados da pesquisa

No caso do QL para o número de estabelecimento é possível observar semelhança com o QL de empregos formais, tendo concentração maior para a indústria extrativa, contudo tendo destaque outros setores como, por exemplo, comércio e serviços. 


\section{Coeficiente de Localização}

Dentre estes indicadores tem-se o coeficiente de localização (CL), que mostra o grau de dispersão relativa dos setores produtivos em determinadas localidades. Assim, é possível dividir o comportamento em dois grupos: setores com maior tendência à concentração espacial; e setores com menor tendência à concentração espacial, que pode ser verificado no quadro 5.

Quadro 5. Coeficiente de Localização do Emprego Formal

\begin{tabular}{|l|l|l|l|}
\hline SETOR & 1990 & 2000 & 2010 \\
\hline EXTR MINERAL & 0,53 & 0,40 & 0,584 \\
\hline IND TRANSF & 0,04 & 0,01 & 0,012 \\
\hline SERV IND UP & 0,01 & 0,01 & 0,009 \\
\hline CONSTR CIVIL & 0,02 & 0,01 & 0,028 \\
\hline COMERCIO & 0,04 & 0,04 & 0,033 \\
\hline SERVICOS & 0,05 & 0,04 & 0,032 \\
\hline ADM PUBLICA & 0,05 & 0,04 & 0,044 \\
\hline AGROPECUARIA & 0,02 & 0,05 & 0,051 \\
\hline TOTAL & 0,05 & 0,04 & 0,036 \\
\hline
\end{tabular}

Fonte: Dados da pesquisa

No quadro 5, é possível notar que para alguns setores em 1990 havia muita concentração em alguns setores enquanto que, em 2010, nota-se uma melhor dispersão entre os setores.

\section{Coeficiente de Especialização}

Para a verificação do comportamento do emprego formal no município foi utilizado como medida regional o coeficiente de especialização (CE), apresentados no quadro 6.

Quadro 6. Coeficiente de Especialização do Emprego Formal

\begin{tabular}{|c|c|c|c|}
\hline SETOR & 1990 & 2000 & 2010 \\
\hline EXTR MINERAL & 0,10 & 0,03 & 0,06 \\
\hline IND TRANSF & 0,08 & 0,04 & 0,05 \\
\hline SERV IND UP & 0,00 & 0,00 & 0,00 \\
\hline CONSTR CIVIL & 0,02 & 0,01 & 0,04 \\
\hline COMERCIO & 0,17 & 0,18 & 0,18 \\
\hline SERVICOS & 0,31 & 0,29 & 0,23 \\
\hline ADM PUBLICA & 0,30 & 0,26 & 0,29 \\
\hline AGROPECUARIA & 0,01 & 0,20 & 0,16 \\
\hline TOTAL & 1,00 & 1,00 & 1,00 \\
\hline
\end{tabular}

Fonte: Dados da pesquisa 
Quanto a especialização da economia local se comparada a do Estado, nota-se uma composição semelhante à do Estado, principalmente nos setores da indústria, ou seja, uma estrutura de mão de obra próxima ao que se observa no estado. No entanto, os setores de serviços, administração pública e agropecuária apresentam indicadores de especialização, contudo, resultados absolutos que não nos permitem considerar a estrutura da mão de obra concentrada nestas atividades (quadro 6).

\section{Conclusão}

A partir do uso de métodos de análise de economia regional, foi possível a construção do quociente locacional de emprego e de empresas, do coeficiente de localização e do coeficiente de especialização de Corumbá levando em consideração os anos de 1990, 2000 e 2010.

Com os dados da RAIS, conclui-se que o perfil de porte das empresas no município é de $98 \%$ de micro e pequenas empresas, apontando a necessidade de construção de caminhos que fortaleçam o empreendedorismo diante deste contexto.

Após isso, identificamos padrões de concentração e de dispersão a partir de atividade econômica no município, ou seja, parte de sua estrutura produtiva, sendo a atividade industrial extrativa a que possui maior capacidade de concentração econômica, ou seja, Corumbá possui uma maior especialização e concentração de atividade econômica envolta da indústria extrativa.

Contudo, em uma análise empírica cabe destacar a participação de outros setores que registraram avanço ao longo dos anos de 2000 e 2010 (serviços públicos, agropecuária, alimentos e bebidas, comércio varejista, construção civil e ensino sendo que, este último volta a configurar como importante setor em 2010.

De modo análogo, concluímos que o setor industrial extrativo, a administração pública e o agronegócio são importantes setores indutores para a economia local, o que fica demonstrado a partir das análises de concentração de atividade econômica.

Atendendo o segundo objetivo proposto, destacamos algumas hipóteses de investimento regionais que podem ser pauta de empreendedorismo no município, pois estarão vocacionadas para as atividades de maior impacto e dinamismo:

$\checkmark \quad$ Energia eólica (indústria de produção) (alta complexidade produtiva)

$\checkmark \quad$ Turismo de contemplação e histórico (baixa complexidade produtiva)

$\checkmark \quad$ Beneficiamento de duas commodities (agro e mineral) (alta complexidade produtiva)

$\checkmark \quad$ Tecnologia da informação (em função das IES) (alta complexidade produtiva)

$\checkmark \quad$ Economia da Cultura (baixa complexidade produtiva)

Neste sentido, é salutar que estes três setores se caracterizam por serem indutores a outros como, por exemplo, comércio e serviços. Ainda, estes três setores possuem incentivos fiscais verticalizados (na esfera federal, estadual e municipal), o que pode contribuir com a possibilidade de atração de investimentos nestas áreas.

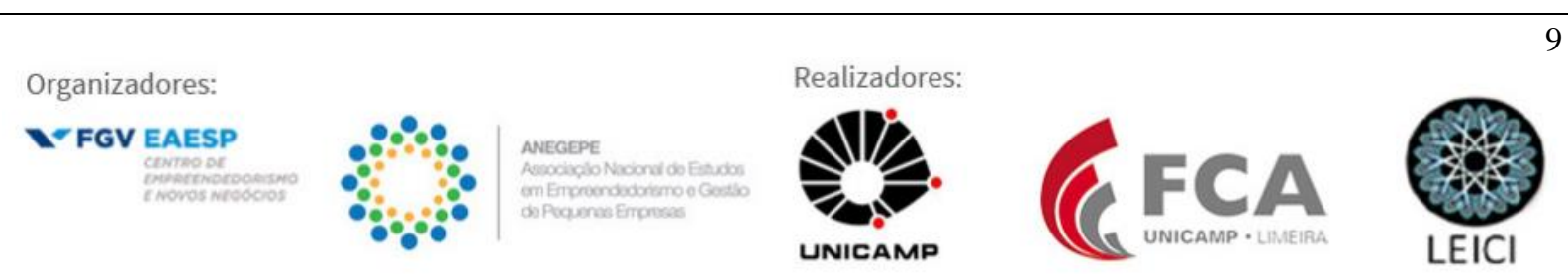




\section{Referências}

ALMEIDA, F. M. VALADARES, J. L. SEDIYAMA, G. A. S. A contribuição do empreendedorismo para o crescimento econômico dos estados brasileiros. Revista de Empreendedorismo e Gestão de Pequenas Empresas, v.6, n.3, p. 466-494, 2017.

CROCCO, M. A. GALINARI, R. SANTOS, F. LEMOS, M. B. SIMOES, R. Metodologia de identificação de aglomerações produtivas locais. Nova Economia, v. 2, p. 211-241, 2006.

GOMES, M. V. P.; ALVES, M. A., FERnANDES, R. J. R. Políticas Públicas de Fomento ao Empreendedorismo e às Micro e Pequenas Empresas. São Paulo: Programa Gestão Pública e Cidadania, 2013.

HADDAD, P. R. (org). Economia Regional: Teorias e Métodos de Análise. Fortaleza: Banco do Nordeste, 1989.

FIGUEIREDO, H. L. OLIVEIRA, M. A. S. Análise de Decomposição Estrutural para a Economia Brasileira entre 1995 e 2009. Revista de Economia, v. 41, n. 2, p. 31-56, 2015.

HERZOG, H.W.; OLSEN, R.J. Shift-share analysis revisited: the allocation effect and the stability of regional structure, a reply. Journal of Regional Science, v.19, n.3, p.393-395, 1979.

INSTITUTO BRASILEIRO DE GEOGRAFIA E ESTATÍSTICA. Contas Regionais. 2015.

LARA, F. FIORI, T. P. ZANIN, V. Notas sobre medidas de concentração e especialização: um exercício preliminar para o emprego no Rio Grande do Sul. Fundação de Economia e Estatística. Porto Alegre-RS, 2010.

LEYDEN, D. P. LINK, A. N. Public Sector Entrepreneurship: U.S. Technology and Innovation Policy. Oxford University Press, 2015.

LIMA, J. F. ALVES, L. R. PIFFER, M. PIACENTI, C. A. Análise regional das mesorregiões do estado do Paraná no final do século XX. Análise econômica, n. 46, p.7-26, 2006.

MINISTÉRIO do Trabalho, RAIS, anos de 1990/2010.

OECD. SMES, entrepreneurship and innovation. Paris: OECD Publishing, 2010.

RODRIK, D. "Structural change, fundamentals and growth: an overview", United States: Institute for Advanced Study. 2013.

SARFATI, G. 2013: Políticas Públicas de Empreendedorismo e de Micro, Pequenas e Médias Empresas (MPMEs): o Brasil em Perspectiva Comparada. Global Entrepreneurship Monitor (GEM) 2017. 
SEBRAE. Anuário do trabalho na micro e pequena empresa: 2010-2011. 4. ed. /Serviço Brasileiro de Apoio às Micro e Pequenas Empresas (Org.); Departamento Intersindical de Estatística e Estudos Socioeconômicos. Brasília, 2012.

SEBRAE. Subsídios para a identificação de clusters no Brasil. 2002.

SIMÕES, R. Métodos de análise regional e urbana: diagnóstico aplicado ao planejamento. Texto para discussão n. 49. Cedeplar-UFMG, 2005.

SOUZA, N. J. Desenvolvimento Regional. São Paulo: Atlas, 2010.

SOUZA, Roosiley dos Santos. Intenção empreendedora: validação de modelo em universidades federais de Mato Grosso do Sul, Brasil./ Roosiley dos Santo Souza. 2015. 113f. Tese (doutorado) - Universidade Nove de Julho - UNINOVE, São Paulo, 2015. 